\title{
Fabrication and Characterization of Ni-Cr Alloy Thin Films for Application to Precision Thin Film Resistors
}

\author{
Boong-Joo Lee* and Paik-Kyun Shin ${ }^{\dagger}$
}

\begin{abstract}
Ni(75 wt.\%)-Cr(20 wt.\%)-Al(3 wt.\%)-Mn(4 wt.\%)-Si(1 wt.\%) alloy thin films were prepared using the DC magnetron sputtering process by varying the sputtering conditions such as power, pressure, substrate temperature, and post-deposition annealing temperature in order to fabricate a precision thin film resistor. For all the thin film resistors, sheet resistance, temperature coefficient of resistance (TCR), and crystallinity were analyzed and the effects of sputtering conditions on their properties were also investigated. The oxygen content and TCR of Ni-Cr-Al-Mn-Si resistors were decreased by increasing the sputtering pressure. Their sheet resistance, TCR, and crystallinity were enhanced by elevating the substrate temperature. In addition, the annealing of the resistor thin films in air at a temperature higher than $300^{\circ} \mathrm{C}$ lead to a remarkable rise in their sheet resistance and TCR. This may be attributed to the improved formation of $\mathrm{NiO}$ layer on the surface of the resistor thin film at an elevated temperature.
\end{abstract}

Keywords : DC magnetron sputtering, Ni-Cr alloy thin films, TCR, Thin film resistor

\section{Introduction}

Analysis of the traction power supply system indicates the calculation of the electrical quantities in railway systems. The traction power system in the electrified railway is comprised of a three-phase receiving unit, facilities including Scott-transformer and auto-transformer to transform voltage level and phase, and the train as consuming electric power. Therefore, the train is the electric load.

The circuit for analysis is made up of a three-phase voltage source represented by a three-phase receiving unit, load represented trains, and line impedance for catenary that is a transmission line for supplying electric power to the train.

Although the circuit element is determined like indicated above, the circuit is not determined due to the unknown state of the train (location, consumed power, and etc.). The location of the train decides the position of load and the consumed power indicates the capacity of load in the circuit. Therefore, Train Performance Simulation (TPS) is used to calculate the consumed power, location and speed of the train based on time. The consumed power, however, is simply calculated by multi-

$\dagger$ Corresponding Author: School of Electrical Engineering, Inha University, 253 Younghyun-dong, Nam-gu, Incheon, Korea 402-751 (shinsensor@inha.ac.kr)

* Department of Electronic Engineering, Namseoul University, 21 Maeju-ri, Seonghwan-eup, Choongnam, Korea 330-607 (bjlee@ $@$ nsu.ac.kr)

Received 10 October 2007 ; Accepted 25 October 2007 plying the mechanical power required for the train propulsion by the ratio in the TPS. This ratio is constant for converting the mechanical power into electric power. Thus, it could make some errors in analysis of the traction power system.

This paper presents the load modeling for the analysis of the electric railway system. The electric load components have different characteristics according to the variation of voltage and frequency. The methods for setting up load modeling may be classified into two categories; the first one is to find an aggregation of each component load modeling, and the other approach is to find parameters to represent load characteristics from field tests [1-2].

This paper proposes the load modeling of the electric locomotive by the parameter identification method. The electric locomotive load is represented as a combination of the static loads and the dynamic loads. The static load is described using polynomial equations and the dynamic load is described using the equivalent induction motor. And the sum of composition rates of each load type is unity.

The pattern search method (PSM) [3] and the recursive least square method (RLS) [4] are applied to the parameter identification methods for the load modeling of an electric locomotive in this paper. To demonstrate the potentiality of the proposed method for load modeling, actual field measurements from the KTX (Korea Train eXpress) is performed. 


\section{Experimental}

A commercially available $\mathrm{Ni}(72.0 \mathrm{wt} . \%)-\mathrm{Cr}(20 \mathrm{wt} . \%)-$ $\operatorname{Al}(3.0 \quad$ wt.\%)-Mn(4.0 wt.\%)-Si(1.0 wt.\%) alloy target (Evanohm) with low TCR $\left(\leq \pm 5 \mathrm{ppm} /{ }^{\circ} \mathrm{C}\right)$ was used for the thin film deposition process. Al2O3 substrates of $3^{\prime \prime} \times 3^{\prime \prime}$ size polished by laser scribing were used for fabrication of test thin film resistor devices and Corning glass substrates were used for thin film property measurements.

The Ni-Cr-Al-Mn-Si alloy thin films were deposited using a DC magnetron sputter (EOS-310, APEX) in the various conditions, which are summarized in Table 1. The NiCr-Al-Mn-Si alloy thin films were then annealed in the temperature range of $150-400^{\circ} \mathrm{C}$ in air and $\mathrm{N} 2$ ambient for $1 \mathrm{~h}$.

Table 1. Ni-Cr-Al-Mn-Si thin film preparation conditions

\begin{tabular}{|c|c|}
\hline Parameter & Condition \\
\hline Substrate Temperature $\left[{ }^{\circ} \mathrm{C}\right]$ & $25-300$ \\
\hline DC Power [W] & $250-550$ \\
\hline Pressure [mTorr] & $5-25$ \\
\hline Ar gas flow [sccm] & 50 \\
\hline Annealing & $\begin{array}{c}150-450\left[{ }^{\circ} \mathrm{C}\right] \\
\text { in air or } \mathrm{N}_{2} / 1 \mathrm{~h}\end{array}$ \\
\hline
\end{tabular}

In the patterning process of the resulting thin films, a positive photoresist (AZ1512) was prepared using a spin coater (WS-400, Laurell), where the step $1(10 \mathrm{sec})$ and step $2(10 \mathrm{sec})$ rotation speed were $500 \mathrm{rpm}$ and $5000 \mathrm{rpm}$, respectively. The photoresist was then treated in the soft baking $\left(100^{\circ} \mathrm{C}, 60 \mathrm{sec}\right.$; hot plate) and hard baking $\left(110^{\circ} \mathrm{C}\right.$, $80 \mathrm{sec}$; hot plate) process after exposure for $40 \mathrm{sec}$ using a mask aligner (MA-6, Karl-Suess). The photoresist was then developed and etched using $\mathrm{Cr}-7 \mathrm{~K}$ etchant, where the etching time was different according to the thin film thickness. The patterned Ni-Cr-Al-Mn-Si alloy thin films were then examined using an optical microscope (Optical Stereoscope, Leica Wild M3Z). The fabrication process of the test thin film resistor is summarized in Fig. 1.

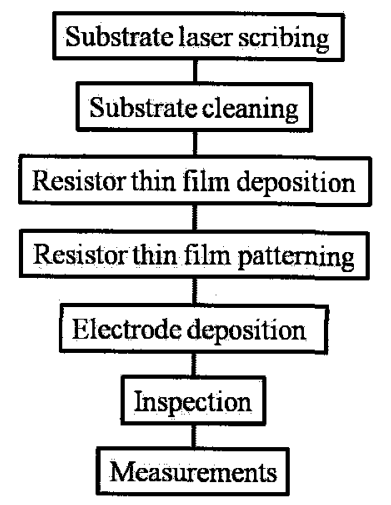

Fig. 1. The fabrication process of the Ni-Cr-Al-Mn-Si thin film resistor.
Microstructure of the Ni-Cr-Al-Mn-Si alloy thin films was analyzed using TEM (transmission electron microscope; Philips CM30) prepared with a thickness of about $20 \mu \mathrm{m}$ using dimple grinder equipment and $\mathrm{Ar}$-ion milling (Gatan, dual ion-mill). At the TEM analysis, SAD (selected area diffraction) and the thin film microstructure were investigated with the acceleration voltage of $200 \mathrm{kV}$. In addition, XRD (X-ray diffraction; Philips X'PERT-MPD), EPMA (electron probe micro analyzer; CAMECA SX-51), and EDS (energy dispersive spectroscopy) measurements were taken for the thin film composition and structural properties investigation: the XRD was done in the range of $2 \theta=20^{\circ}-100^{\circ}$ using a $\mathrm{Cu}$ target and the EPMA was done using $20 \mu \mathrm{m}$ beam of $15 \mathrm{keV} / 20 \mathrm{nA}$. Also, oxygen content of the Ni-Cr-Al-Mn-Si alloy thin films was investigated using the RBS (Rutherford Backscattering Spectrometry) method. Sheet resistance and thickness of the thin films were measured using a 4-Point probe (Chang Min Tech) and thickness profiler (Dektak3, $\alpha$-step), respectively.

Structure of the test thin film resistor was designed as follows. Generally, resistance can be calculated using Eq.1: $\rho$ is specific resistivity $(\Omega \cdot \mathrm{cm}), L$ is length of resistor $(\mathrm{cm})$, $t$ is thickness of thin film resist $(\mathrm{cm})$, and $W$ is width of thin film (cm).

$$
R=P \cdot \frac{L}{t \cdot W}
$$

Because the sheet resistance Rs $(\Omega /$ ) times $t$ (thin film thickness) equals to the specific resistivity, Eq.1 can be rewritten as Eq.2.

$$
R=R_{S} \cdot \frac{L}{W}
$$

For a resistor cell of which the length is equal to the width $(\mathrm{L}=\mathrm{W} \cdot \mathrm{N})$, Eq. 2 can be rewritten as Eq.3.

$$
R=R_{S} \cdot N
$$

Considering Eq.3, three types of total resistance of the test thin film resistor $(0.5,1$, and $1.5 \mathrm{k} \Omega$ ) was designed based on the thin films with sheet resistance of $27 \Omega /$ and thickness of $2000 \AA$. In addition, the size of each specimen was designed as $2 \mathrm{~mm} \times 4 \mathrm{~mm}$ in order to simplify the TCR measurement. The shape of the resistor thin film was planned as line type with line widths of $114 \mu \mathrm{m}, 55 \mu \mathrm{m}$, and $37 \mu \mathrm{m}$. Fig. 2 presents the schematic of the resistor cell structure.

The TCR of the resulting test thin film resistors was measured using a TCR measurement system (4220A, $\mathrm{S} \& \mathrm{~A}$ ), where the temperature was set for $10 \mathrm{~min}$ duration at the measurement. For each test thin film resistor, TCR 
was calculated using Eq.4 after resistance measurement at $25^{\circ} \mathrm{C}(\mathrm{R} 25)$ and $85^{\circ} \mathrm{C}(\mathrm{R} 85)$. Here TCR $\left(\mathrm{ppm} /{ }^{\circ} \mathrm{C}\right)$ is the temperature coefficient of resistance, $\Delta \mathrm{R}$ is the resistance change in a specific temperature range $\left(25^{\circ} \mathrm{C}-85^{\circ} \mathrm{C}\right)$, and $\Delta \mathrm{T}$ is temperature difference, respectively.

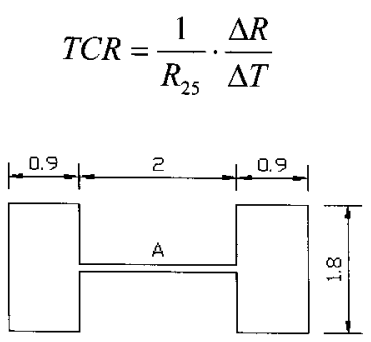

A : $114 \mathrm{um}$

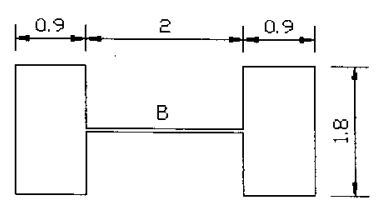

B : 55 um

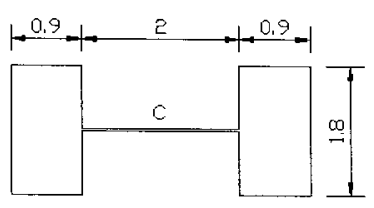

c: 37$\lrcorner m$

Fig. 2. A schematic diagram of the thin film resistor cell structure.

\section{Results and Discussions}

\subsection{Analysis of target and thin film}

In order to investigate the material homogeneity and composition of the Ni-Cr-Al-Mn-Si alloy target, EPMA and microstructures such as the BSE (back scattered electron) image of SEM (scanning electron microscope) were analyzed, which are shown in Fig. 3 and Table 2.

Table 2. Composition of the NI-Cr-Al-Mn-Si alloy target and the resulting thin film

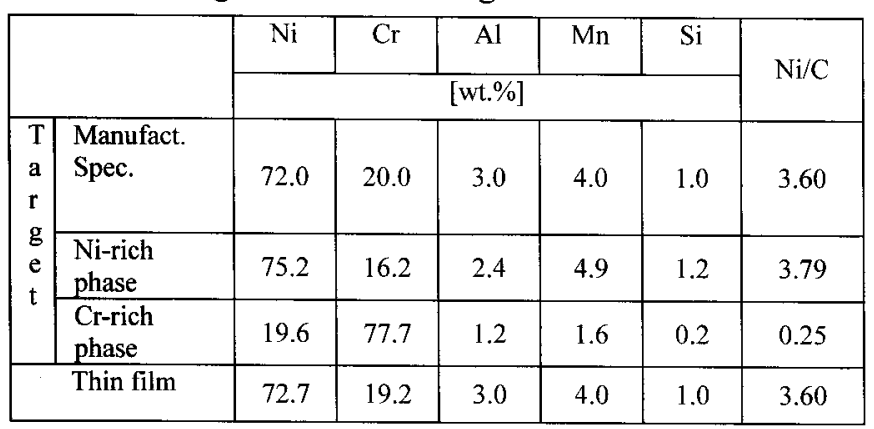

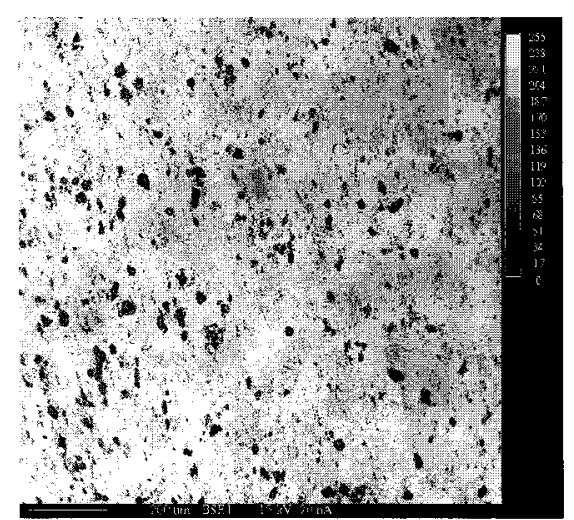

Fig. 3. BSE (back scattered electron) image from the SEM analysis of the $\mathrm{Ni}-\mathrm{Cr}-\mathrm{Al}-\mathrm{Mn}-\mathrm{Si}$ thin film.

As is presented in Fig. 3, the Ni-Cr-Al-Mn-Si alloy target is not composed homogenously but rather detached with two phases of Ni-rich part (light) and Cr-rich part (dark). Considering the BSE results summarized in Table 2, the $\mathrm{Ni} / \mathrm{Cr}$ composition ratio (3.60) in the Ni-rich phase is similar to that (3.79) in the manufacturer's specification, while the $\mathrm{Ni} / \mathrm{Cr}$ composition ratio $(0.25)$ in the $\mathrm{Cr}$-rich phase is remarkably different. Furthermore, the $\mathrm{Cu}$ and $\mathrm{Al}$ element contents are also lower than as indicated in the target manufacturer's specification. The composition of the resulting $\mathrm{Ni}-\mathrm{Cr}-\mathrm{Al}-\mathrm{Mn}-\mathrm{Si}$ alloy thin film deposited with the sputtering condition (dc power $250 \mathrm{~W}$, pressure of $5 \mathrm{mTorr}$, Ar flow rate of $50 \mathrm{sccm}$ ) is also shown in Table 3, which indicates that the resulting thin film composition (72.7wt $\% \mathrm{Ni}-19.2 \mathrm{wt} \% \mathrm{Cr}-3.0 \mathrm{wt} \% \mathrm{Al}-4.0 \mathrm{wt} \% \mathrm{Mn}-1.0 \mathrm{wt} \% \mathrm{Si})$ is almost the same as that of the target specification within error extent of the EPMA analysis.

\subsection{Analysis of annealed thin films}

Considering the thermal stability and post deposition process, annealing treatment of thin films is essential. Fig. 4 shows the XRD patterns of the as-deposited and annealed $\mathrm{Ni}-\mathrm{Cr}-\mathrm{Al}-\mathrm{Mn}-\mathrm{Si}$ alloy thin films. The unmarked diffraction peaks are considered as for the alumina substrate, while diffraction peaks are indicating the cubic phases (filled circle) and rhombehedral phases (filled square) of the Ni$\mathrm{Cr}-\mathrm{Al}-\mathrm{Mn}-\mathrm{Si}$ alloy thin films. The as-deposited $\mathrm{Ni}(72$ wt.\%)-Cr (20 wt.\%)-Cu (3 wt.\%)-Mn (4 wt.\%)-Si (1 wt.\%) thin film reveals a cubic crystalline structure, and the sample annealed at $300^{\circ} \mathrm{C}$ shows similar diffraction peaks. On the contrary, the sample annealed at $400^{\circ} \mathrm{C}$ shows a mixture of cubic phases and $\mathrm{NiO}$ rhombohedral phases, which is considered as the result of thin film oxidation during the annealing process. 


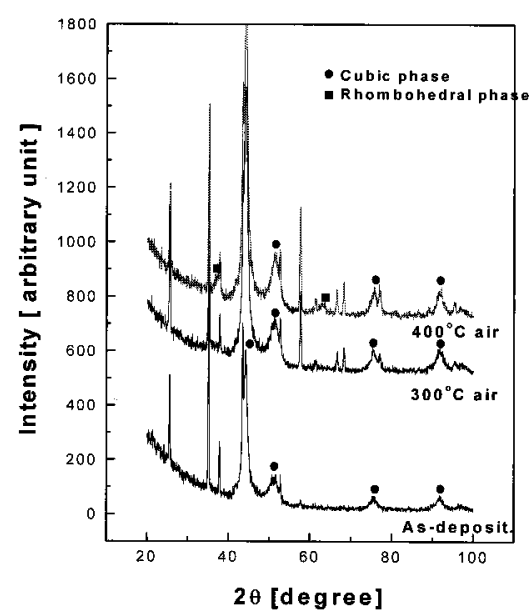

Fig. 4. XRD patterns of the as-deposited and annealed NiCr-Al-Mn-Si thin films.

\subsection{Physical and electrical properties}

Fig. 5 indicates relationship between sputtering time and thickness of the Ni-Cr-Al-Mn-Si alloy thin films, which were deposited at the sputtering condition of DC $250 \mathrm{~W}$ (power), $25 \mathrm{mTorr}$ (pressure), $50 \mathrm{sccm}$ (Ar flow rate). The thin film thickness reveals typical sputtering characteristic [9] and is linearly dependent on the sputtering time with deposition rate of about $350 \AA \mathrm{min}$.

Fig. 6 reveals the sheet resistance variations depending on thickness changes for the Ni-Cr-Al-Mn-Si alloy thin films prepared at the sputtering condition of DC $250 \mathrm{~W}$ (power), $25 \mathrm{mTorr}$ (pressure), $50 \mathrm{sccm}$ (Ar flow rate). Sheet resistance is closely dependent on the thin film thickness and decreases drastically up to the thin film thickness of $2000 \AA$. In addition, the thin film deposited on alumina substrate shows larger sheet resistance than those deposited on corning glass substrate, which is possibly due to the higher surface roughness of the alumina substrate.

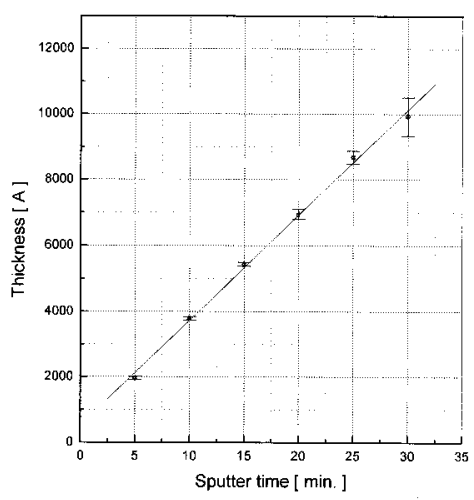

Fig. 5. Relationship between the sputtering time and resulting Ni-Cr-Al-Mn-Si thin film thickness.

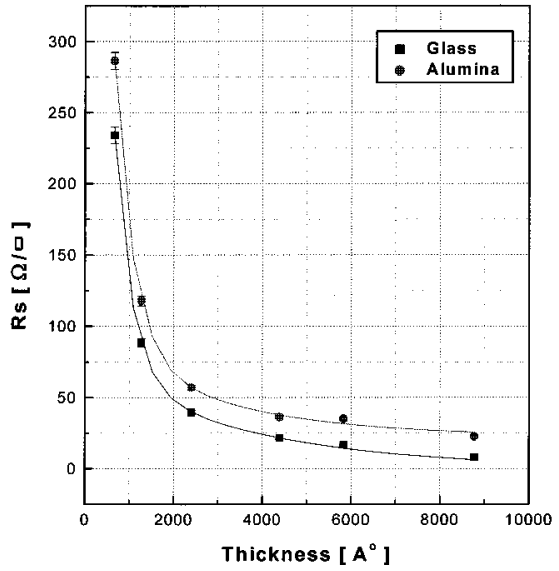

Fig. 6. Sheet resistance variation depending on thickness of the Ni-Cr-Al-Mn-Si thin film.

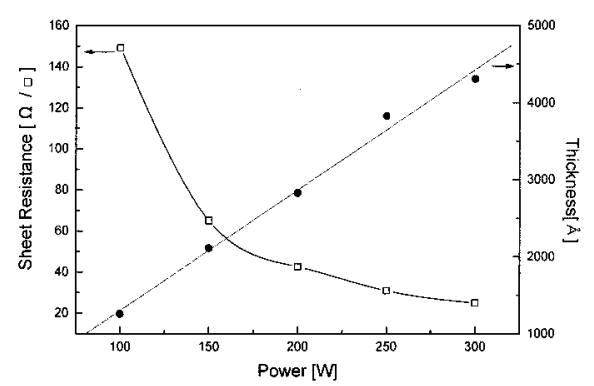

Fig. 7. Effect of the sputtering power variation on the thickness and sheet resistance of the Ni-Cr-Al-MnSi thin film.

Effect of the sputtering power variation on thickness and sheet resistance of the Ni-Cr-Al-Mn-Si alloy thin films are indicated in Fig. 7, which were deposited at the sputtering condition of DC $250 \mathrm{~W}$ (power), $25 \mathrm{mTorr}$ (pressure), 50 $\mathrm{sccm}$ (Ar flow rate), and $10 \mathrm{~min}$ (deposition time), respectively. Again, thin film thickness increases linearly with deposition time. Sheet resistance decreases exponentially with increase of sputtering power and decreases drastically for samples prepared with up to $250 \mathrm{~W}$ (power), and then the decrease tendency declines after the $250 \mathrm{~W}$. Therefore, the DC power of $250 \mathrm{~W}$ was applied to the Ni-Cr-Al-Mn$\mathrm{Si}$ alloy thin film deposition process for fabrication of test thin film resistor samples.

In order to find the optimal sputtering condition for the $\mathrm{Ni}-\mathrm{Cr}-\mathrm{Al}-\mathrm{Mn}-\mathrm{Si}$ alloy thin film, the RBS analysis was carried out in terms of oxygen partial pressure, which is shown in Fig. 8. For the samples prepared at the oxygen partial pressure conditions of 25 mTorr and 15 mTorr, the oxygen peaks are clearly to be observed, while it is not the case for the sample prepared at the oxygen partial pressure of 5 mTorr. After the quantitative analysis concerning the oxygen content in the Ni-Cr-Al-Mn-Si alloy thin films 
through RBS, the oxygen content in the thin films were 8.9 wt.\% (25 mTorr), 8.5 wt.\% (15 mTorr), and 1.5 wt.\% (5 mTorr), respectively.

In addition, Fig. 9 indicates the TCR of the test thin film resistors, of which the thin films were prepared with the same partial oxygen pressure conditions in Fig. 8, namely, $25 \mathrm{mTorr}, 15 \mathrm{mTorr}$, and $5 \mathrm{mTorr}$. As the oxygen partial pressure decreases, the TCR decreases drastically as +105 $\mathrm{ppm} /{ }^{\circ} \mathrm{C}$ ( $\left.25 \mathrm{mTorr}\right),+85 \mathrm{ppm} /{ }^{\circ} \mathrm{C}(15 \mathrm{mTorr})$, and +54 $\mathrm{mTorr} /{ }^{\circ} \mathrm{C}$, respectively. As the RBS analysis results indicates, the oxygen partial pressure caused the decrease of oxygen content in the thin film, which in turn results in remarkable decrease of the TCR. Considering these results, the oxygen partial pressure for the improved thin film resistors was chosen as $5 \mathrm{mTorr}$.
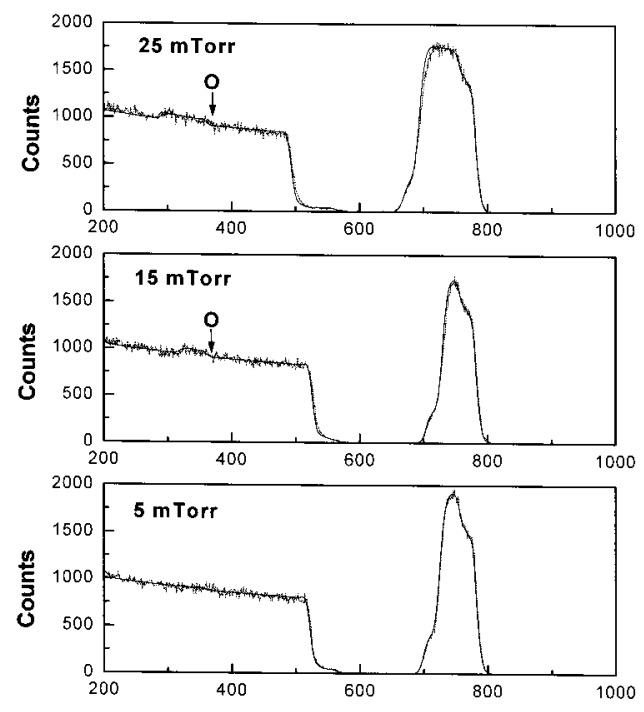

Fig. 8. RBS spectrum of the Ni-Cr-Al-Mn-Si thin films prepared with various sputtering pressure.

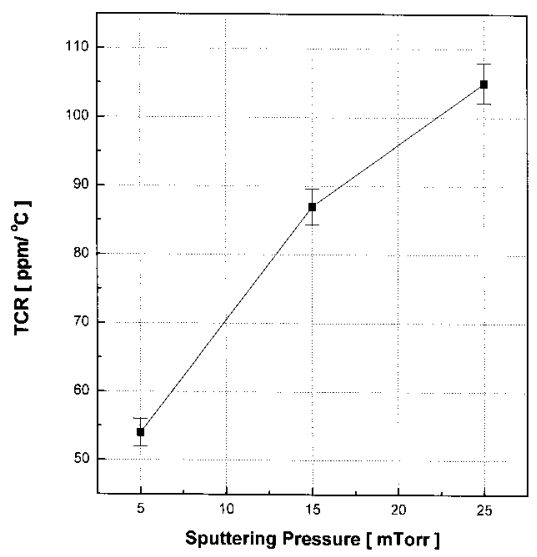

Fig. 9. TCR of the thin film resistors with Ni-Cr-Al-Mn-Si thin films prepared with various sputtering pressure.

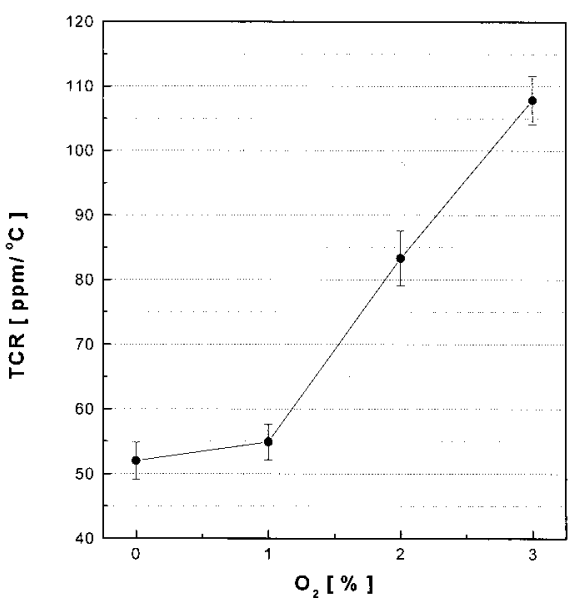

Fig. 10. TCR of the thin film resistors with Ni-Cr-Al-MnSi thin films prepared with various oxygen content in Ar plasma ambient.

Figure 10 shows the TCR of the test thin film resistors based on the Ni-Cr-Al-Mn-Si alloy thin films prepared at the process conditions of $250 \mathrm{~W}$ DC power, $25^{\circ} \mathrm{C}$ substrate temperature, and $6.5 \mathrm{mTorr}$ pressure $\left(\mathrm{Ar}+\mathrm{O}_{2}\right)$. As the oxygen gas content contained in $\mathrm{Ar}$ gas rises from $0 \%$ up to $3 \%$, oxygen content in the resulting resistor thin film rises and the increase tendency is remarkable from above $1 \%$ oxygen content: while the TCR for the sample prepared with $0 \%$ is $+54 \mathrm{ppm} /{ }^{\circ} \mathrm{C}$, the TCR for the sample prepared with $3 \%$ is $+108 \mathrm{ppm} /{ }^{\circ} \mathrm{C}$. The results indicate that the TCR of the test thin film resistor is closely related to the oxygen content in the ambient gas, which is similar to the case of sputtering pressure (Figs. 8, 9).

In order to investigate the effect of substrate temperature and sputtering power, TEM micro analysis was done for the Ni-Cr-Al-Mn-Si alloy thin films as shown in Fig. 11: (a) and (b) are bright filed (BF) image and dark filed (DF) image of the sample prepared with substrate temperature of $25^{\circ} \mathrm{C}$ and power of $250 \mathrm{~W}$; (c) and (d) are BF and DF images of the sample prepared with substrate temperature of $300^{\circ} \mathrm{C}$ and power of $550 \mathrm{~W}$, respectively.

In case of the sample prepared with higher substrate temperature and higher power (Fig. 11d), the grain size is relatively larger than that of the sample prepared with lower substrate temperature and lower power (Fig. 11b), which implies that the preparation condition of higher substrate temperature and higher power resulted in further progress in thin film crystallization. These results coincide with the electron diffraction pattern, where the sputtering condition of higher substrate temperature and higher power resulted in again larger grain growth verified by more lucid spot of the ring pattern. 


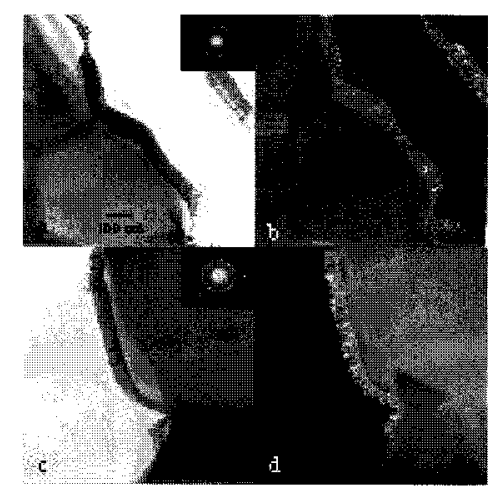

Fig. 11. TEM images of the Ni-Cr-Al-Mn-Si thin films:

(a) prepared at $\mathrm{T}_{\mathrm{s}}=25^{\circ} \mathrm{C}$ and $250 \mathrm{~W}$ power, bright image;

(b) prepared at $\mathrm{T}_{\mathrm{s}}=25^{\circ} \mathrm{C}$ and $250 \mathrm{~W}$ power, dark image;

(c) prepared at $\mathrm{T}_{\mathrm{s}}=300^{\circ} \mathrm{C}$ and $550 \mathrm{~W}$ power, bright image;

(d) prepared at $\mathrm{T}_{\mathrm{s}}=300^{\circ} \mathrm{C}$ and $550 \mathrm{~W}$ power, dark image.

The effect of the post deposition annealing of the $\mathrm{Ni}-\mathrm{Cr}$ Al-Mn-Si alloy thin film on the sheet resistance and TCR of the resulting thin film resistor are shown in Fig. 12 and Fig. 13, respectively: $\mathrm{Ni}(72$ wt.\%)-Cr(20 wt.\%)-Al(3 wt.\%)-Mn(4 wt.\%)-Si(1 wt.\%) target was used for thin film sputter deposition at the condition of pressure of $5 \mathrm{mTorr}$, Ar flow rate of $50 \mathrm{sccm}, \mathrm{DC}$ power of $250 \mathrm{~W}$, and $2 \mathrm{~min}$ sputtering time; the thin films were then annealed for $1 \mathrm{~h}$ either in air or in $\mathrm{N}_{2}$ ambient. As indicated in Fig. 12, the sheet resistance of the thin films is relatively constant at the annealing temperature of up to $350^{\circ} \mathrm{C}$ in $\mathrm{N}_{2}$ ambient, while in the case of annealing in air, it increases with the substrate temperature and increases remarkably from the temperature of $300^{\circ} \mathrm{C}$.

It is thought that the annealing of the thin film in air at higher than $300^{\circ} \mathrm{C}$ would be closely related to increased oxidation of the thin film. The TCR of the resulting test thin film resistor (Fig. 13) increases with the annealing temperature: for the sample with the thin film annealed in $\mathrm{N}_{2}$ ambient it increases linearly, while for the sample with the thin film annealed in air ambient it increases more remarkably. Again the annealing of the thin film in air at the temperature higher than $300^{\circ} \mathrm{C}$ resulted in larger increase of the TCR as it is expected in the case of sheet resistance.

In general, increase of the substrate temperature has been carried out for improvement of thin film adhesion and thin film structure. In order to examine the substrate temperature effect on the TCR of the resulting thin film resistor, the Ni-Cr-Al-Mn-Si thin films were prepared at the substrate temperature of $25^{\circ} \mathrm{C}, 100^{\circ} \mathrm{C}, 200^{\circ} \mathrm{C}$ and $300^{\circ} \mathrm{C}$, and then annealed in air for $1 \mathrm{~h}$ at $200^{\circ} \mathrm{C}$ and $300^{\circ} \mathrm{C}$. Fig. 14 indicates the TCR values of the resulting thin film resistor samples, where the thin film preparation condition was DC power of $250 \mathrm{~W}$, pressure of $5 \mathrm{mTorr}$, and Ar flow rate of $50 \mathrm{sccm}$. Observing the TCR of the samples with annealed thin films in air, the higher the substrate temperature is, the smaller the TCR variation range became. Furthermore, the TCR of the samples with annealed thin films in air de- crease with increase of the substrate temperature, which implies that the substrate temperature and subsequent thermal stress would cause a denser and more stable microstructure of the thin films. In case of the resistor samples with thin films prepared at $25^{\circ} \mathrm{C}$, the post deposition annealing resulted in relatively remarkable variation of the TCR, while the effect of the post deposition annealing resulted in less variation of the TCR for the resistor samples with thin films prepared at higher substrate temperatures.

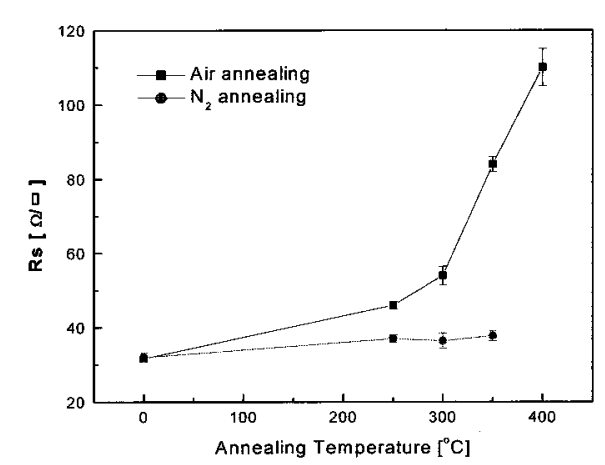

Fig. 12. Sheet resistance of the Ni-Cr-Al-Mn-Si thin films annealed at various temperatures in air and $\mathrm{N}_{2}$ ambient.

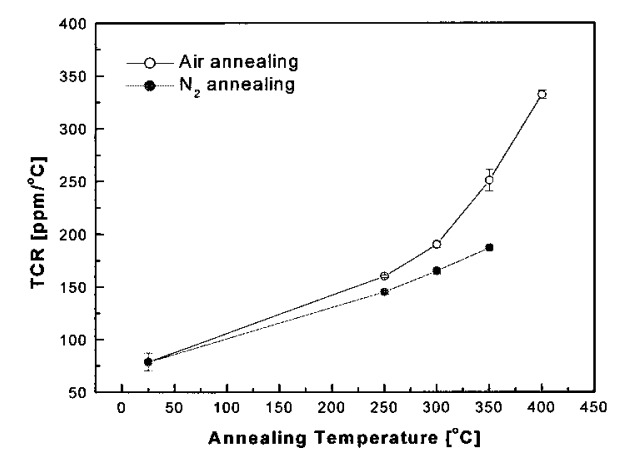

Fig. 13. TCR of the thin film resistor samples with the $\mathrm{Ni}$ $\mathrm{Cr}-\mathrm{Al}-\mathrm{Mn}-\mathrm{Si}$ thin films annealed at various temperatures in air and $\mathrm{N}_{2}$ ambient.

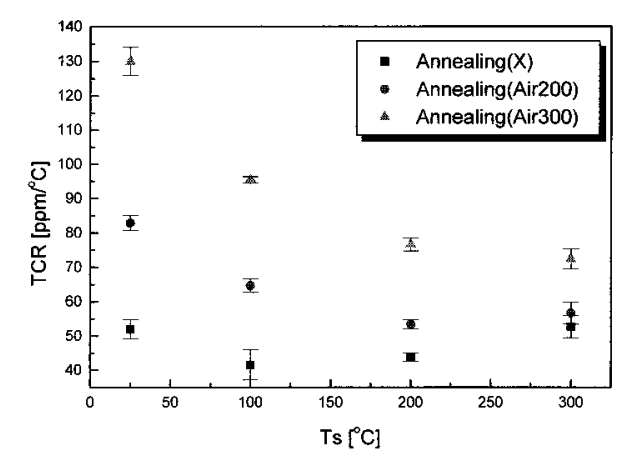

Fig. 14. TCR of the thin film resistor samples with the Ni-CrAl-Mn-Si thin films prepared at various substrate temperatures and annealed in air and $\mathrm{N}_{2}$ ambient. 


\section{Summary and Conclusion}

In this report, a $\mathrm{Ni}(75 \mathrm{wt} . \%)-\mathrm{Cr}(20 \mathrm{wt} . \%)-\mathrm{Al}(3 \mathrm{wt} . \%)-$ $\mathrm{Mn}(4 \mathrm{wt} . \%)-\mathrm{Si}(1 \mathrm{wt. \%}$ ) alloy target was used for DC magnetron sputter deposition of the Ni-Cr-Al-Mn-Si thin films with various sputtering conditions for development of a precision thin film resistor. The effect of the sputtering condition on the Ni-Cr-Al-Mn-Si thin film properties and the TCR of the resulting test thin film resistor samples were investigated. The physical and electrical properties of the thin films and thin film resistor samples reveal following results.

1) After the EPMA results, the content of the Ni-Cr-Al$\mathrm{Mn}$-Si alloy target coincide with that of the deposited thin film resistor.

2) The larger the substrate roughness is, the higher is the sheet resistance of the resulting thin film.

3) The lower the oxygen content in the thin film, the lower the sheet resistance of the thin film and the TCR of the resulting thin film resistor becomes.

4) In case of the post deposition annealing at higher temperature than $300^{\circ} \mathrm{C}$, the sheet resistance of the thin films and the TCR of the resulting thin film resistor increased more remarkably for the samples annealed in air ambient than those annealed in $\mathrm{N}_{2}$ ambient. These results are thought to be caused by enhanced $\mathrm{NiO}$ oxidation through the post deposition annealing in air.

5) During the resistor thin film formation, the substrate temperature rise caused increased thermal stress and alteration of the microstructure of the resulting thin film, and the higher the substrate temperature is, the denser and more stable the microstructure of the thin films becomes. The increased substrate temperature resulted in less variation of the TCR of the resulting thin film resistor, which would be thought to be resulted from the enhanced oxidation through the post deposition annealing and thermal stress though the substrate temperature increase.

\section{Acknowledgements}

The manuscript was recommended by Editor Jin-Seok Park. The work was supported by the INHA University.

\section{References}

[1] Neelkanth G. Dhere et.al, "Composition and temperature coefficient of resistance of Ni-Cr thin films", Thin Solid Films, vol. 59, no. 1, pp. 33-41, April (1979).

[2] M.A. Bayne, "Al-doped Ni-Cr for temperature coef- ficient of resistance control in hybrid thin-film resistors", J. Vac. Sci. Technol., vol. A4, no. 6, pp. 31423145, November (1986).

[3] J.H. Mooij et. al., "Structural and electrical properties of sputtered CrNi films", J. Vac. Sci. Technol., vol. 9, no. 1, pp. 446-449, January (1972).

[4] A. Belu-Marian et.al., "Electrical properties and structural defects of Ni-Cr thin films", Thin Solid Films, vol. 139, no. 1, pp. 15-24, May (1986).

[5] M.I. Birjega et.al., "Crystallization of amor-phous sputtered 55\%Cr-45\%Ni thin films", Thin Solid Films, vol. 92, no. 4, pp. 315-322, June (1982).

[6] D. M. Buczek, "Thin-film NiCr resistor", J.Vac. Sci. Technol., vol. 15, no. 2, pp. 370-372, March (1978).

[7] M. Koltai et. al., "Segregation phenomena in thin film NiCr layers", Vacuum, vol. 33, no. 1-2, pp. 49-52, January-February (1983).

[8] W. Pitschke et. al., "Phase formation process of sputtered $\operatorname{NiCr}(37: 63)$ thin films", Fresenius J. Anal. Chem., vol. 361, no. 6-7, pp. 608-609, August (1998).

[9] Young-Wook Choi and Jeehyun Kim, "Sputtering technique of magnesium oxide thin film for plasma display panel applications", Journal of Electrical Engineering \& Technology, vol. 1, no. 1, pp. 110-113, March (2006).

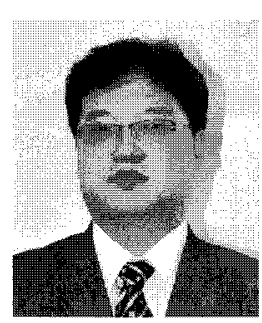

\section{Boong-Joo Lee}

He received his B.S., M.S, and Ph.D degrees in Electrical Engineering from Inha University, Korea in 1996, 1998, and 2003 respectively. He served as a Senior Researcher in the Digital Display Research Center of the LG Electronics Company from 2004-2007. Since 2007 he has been a fulltime Lecturer in the Department of Electronic Engineering at Namseoul University, Korea. His interests include electronic devices, sensors, and flat panel displays.

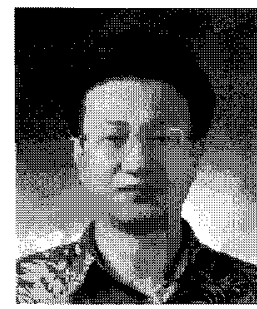

\section{Paik-Kyun Shin}

He received his B.S. and M.S. degrees in Electrical Engineering from Inha University, Korea in 1990 and 1992. He received his Doctor of Engineering degree in Electrical Engineering from the Friedrich-Alexander University, Erlangen-Nuernberg, Germany in 2000 . He was a foreign visiting Researcher at the Kumamoto University, Japan from 2002-2004. Since 2004 he has been an Assistant Professor in the School of Electrical Engineering at Inha University. His interests include electronic devices, sensors, flat panel displays, and plasma technologies. 